\title{
Experiência de uma abordagem prática do PIBID em sala de aula no Ensino de
}

\section{Botânica}

\author{
Experience of a practical approach to PIBID in the classroom in teaching Botany \\ Experiencia de un enfoque práctico de PIBID en el aula en la enseñanza de Botánica
}

Recebido: 06/05/2021 | Revisado: 13/05/2021 | Aceito: 14/05/2021 | Publicado: 30/05/2021

\author{
Antônio Reis de Sousa \\ ORCID: https://orcid.org/0000-0002-3341-4301 \\ Universidade Federal do Piauí, Brasil \\ E-mail: antoniosousa0601@gmail.com \\ Antônia Alikaene de Sá \\ ORCID: https://orcid.org/0000-0003-2479-2324 \\ Universidade Federal do Piauí, Brasil \\ E-mail: allyknsa@hotmail.com \\ Amanda Meneses da Silva \\ ORCID: https://orcid.org/0000-0001-6949-3411 \\ Universidade Federal do Piauí, Brasil \\ E-mail: amandamenesesmoura@gmail.com \\ Fernanda Beatriz do Nascimento \\ ORCID: https://orcid.org/0000-0002-6625-6944 \\ Universidade Federal do Piauí, Brasil \\ fernandabeatrizncm42@gmail.com \\ Jessicléia Rodrigues dos Santos \\ ORCID: https://orcid.org/0000-0002-2543-5217 \\ Universidade Federal do Piauí, Brasil \\ E-mail: jessicleia_rodrigues@ hotmail.com \\ Rafaela de Brito Vieira \\ ORCID: https://orcid.org/0000-0001-5918-2804 \\ Universidade Federal do Piauí, Brasil \\ E-mail: rafinhabritto18@gmail.com \\ Maria Lidiana de Lima Veloso \\ ORCID: https://orcid.org/0000-0001-8346-123X \\ Universidade Federal do Piauí, Brasil \\ E-mail: lilidianana@gmail.com \\ Luzia de Kássia Meneses de Aquino \\ ORCID: https://orcid.org/0000-0003-0090-3819 \\ Rede Básica de Ensino - SEDUC, Brasil \\ E-mail: kassinhaluzia@gmail.com \\ Leonardo Henrique Guedes de Morais Lima \\ ORCID: https://orcid.org/0000-0001-7488-0854 \\ Universidade Federal do Piaú, Brasil \\ E-mail: leonardolima@ufpi.edu.br
}

\begin{abstract}
Resumo
Aulas práticas são essenciais para a compreensão dos conteúdos da área da Biologia, em especial da Botânica. O presente artigo objetivou apresentar uma metodologia de ensino na área de botânica, a partir de uma prática realizada por discentes do PIBID da Universidade Federal do Piauí - CSHNB, bem como trazer reflexões acerca dos conhecimentos relacionados às metodologias dessa área. Para a realização deste trabalho, adotou-se uma metodologia de pesquisa de campo e em seguida uma análise quali-quantitativa, utilizando-se uma ficha de percepções provenientes da comunicação verbal e não verbal dos alunos e de seu envolvimento na aula, tais como comportamentos, questionamentos, expressões corporais e comentários. Obteve-se como resultados a participação de todos os alunos da turma, os quais puderam visualizar e distinguir os diversos grupos de plantas estudados dentro do ensino de Botânica através de exemplares vivos e de algumas estruturas de plantas coletadas na região próxima ao colégio, o que aproximou o conteúdo com a realidade dos alunos. Ademais, vários trabalhos científicos abordam a necessidade de trabalhar a parte prática dos conteúdos dentro do contexto social dos alunos, o que corrobora a realização deste estudo visando demonstrar a importância da prática para o ensino e aprendizagem significativos.

Palavras-chave: Aluno; Contexto escolar; Ensino; Experiências educativas formativas; Grupos de plantas.
\end{abstract}




\begin{abstract}
Practical classes are essential for understanding the contents of the Biology area, especially Botany. This article aimed to present a teaching methodology in the field of botany, based on a practice carried out by PIBID students at the Federal University of Piauí - CSHNB, as well as to bring reflections on the knowledge related to methodologies in this area. To carry out this work, a field research methodology was adopted and then a qualitative and quantitative analysis, using a form of perceptions from the students' verbal and non-verbal communication and their involvement in the class, such as behaviors, questions, body expressions and comments. The results obtained were the participation of all students in the class, who were able to visualize and distinguish the various groups of plants studied within the teaching of Botany through live specimens and some plant structures collected in the region close to the school, which brought the content closer to the students' reality. In addition, several scientific works address the need to work the practical part of the contents within the social context of the students, which corroborates the realization of this study aiming to demonstrate the importance of the practice for the significant teaching and learning.
\end{abstract}

Keywords: Student; School context; Teaching; Formative educational experiences; Groups of plants.

\title{
Resumen
}

Las clases prácticas son fundamentales para comprender los contenidos del área de Biología, especialmente Botánica. Este artículo tuvo como objetivo presentar una metodología de enseñanza en el campo de la botánica, basada en una práctica realizada por estudiantes de PIBID de la Universidad Federal de Piauí - CSHNB, así como traer reflexiones sobre los conocimientos relacionados con las metodologías en esta área. Para llevar a cabo este trabajo se adoptó una metodología de investigación de campo y luego un análisis cualitativo y cuantitativo, utilizando una forma de percepciones de la comunicación verbal y no verbal de los estudiantes y su implicación en la clase, como comportamientos, preguntas, expresiones corporales y comentarios. Los resultados obtenidos fueron la participación de todos los alumnos de la clase, quienes pudieron visualizar y distinguir los distintos grupos de plantas estudiadas dentro de la enseñanza de la Botánica a través de especímenes vivos y algunas estructuras vegetales recolectadas en la región cercana a la escuela, lo que trajo la contenidos más cercanos a la realidad de los estudiantes. Además, varios trabajos científicos abordan la necesidad de trabajar la parte práctica de los contenidos dentro del contexto social de los estudiantes, lo que corrobora la realización de este estudio con el objetivo de demostrar la importancia de la práctica para la enseñanza y el aprendizaje significativos.

Palabras clave: Estudiante; Contexto escolar; Enseñanza; Experiencias educativas formativas; Grupos de plantas.

\section{Introdução}

O ensino de botânica na Educação Básica, na maioria dos casos, ainda está distante de atingir os objetivos esperados em um processo de ensino-aprendizagem significativo e transformador (Ursi et al., 2018). Pois se trata de conceitos considerados, muitas vezes, de difícil compreensão, ou de difícil acesso, mas que na verdade se fazem necessários para a construção de conhecimentos científico-biológicos e na formação de sujeitos críticos e conhecedores do lugar onde habitam (Dutra \& Costa Güllich, 2016).

A profissão docente instiga uma responsabilidade ao conectar-se ao aprendizado e à educação dos indivíduos, nos diálogos geracionais e projetos de futuro, nos quais é preciso possibilitar aprendizados que vão além da intervenção das disciplinas científicas, mas que abordem práticas sociais em sua concretude (Noronha et al., 2020). Para tanto, é necessário a discussão sobre possibilidades pedagógicas capazes de aproximar a botânica dos estudantes e de seus professores, fazendo que o processo de seu ensino-aprendizagem seja mais motivador e efetivo (Ursi et al., 2018).

No ensino tradicional o aprendizado dos alunos geralmente fica reduzido a decorar nomes complicados e conceitos para serem aprovados em testes, sem relacionarem o conhecimento com o seu cotidiano, com os fenômenos que regem suas vidas e a dos seres que os cercam (Sobral et al., 2018)

O processo educacional necessita da utilização de diferentes metodologias de ensino, como forma de despertar o interesse e a participação dos alunos nas aulas, oportunizando a utilização de suas experiências, curiosidades e necessidades, resultando na construção de uma aprendizagem significativa (Fischer et al., 2019). A biologia traz para o professor desta área, diversos meios de se constatar a veracidade dos conteúdos estudados de maneira teórica em sala de aula, através das aulas práticas e experimentais, tornando de suma importância integrar teoria à prática (Interaminense, 2019). 
Dessa forma, as aulas práticas, como método didático, se tornam decisivas para o aprendizado das Ciências, pois contribuem para a formação científica, tendo em vista que aguça a observação, manipulação e construção de modelo, as quais permitem ao estudante observar, vivenciar e discutir o conjunto de experiências e fenômenos biológicos e físico-químicos relacionados com seu cotidiano, vinculando experimentos de observação/atuação e complementando os estudos teóricos (Borges et al., 2019).

Andrade e Massabini (2011), trazem em seu estudo que os professores afirmam valorizar as atividades práticas e entendem a necessidade de mais atividades desse tipo, porém, ficam angustiados por não conseguirem desenvolvê-las nas condições de trabalho. As dificuldades mais relatadas para a realização das aulas práticas são: a falta de tempo para organizar a aula, a ausência de espaço adequado, o grande número de alunos por sala e a falta de formação adequada para o uso desse recurso didático (Lima et al., 2013).

A falta de atividades práticas de diferentes modos e o pouco uso de tecnologias, especialmente as digitais, tão íntimas aos estudantes, representam barreiras no ensino de botânica (Ursi et al., 2018). Para suprir essas dificuldades, a atividade docente requer estratégias, ferramentas e habilidades que se tecem, de maneira particular, no contexto da vida e da formação acadêmica (Noronha et al., 2020).

Segundo Santana (2011), as justificativas para a ausência ou a baixa frequência de atividades práticas na rotina do ensino de Ciências podem ser agrupadas em três grandes categorias: formação acadêmica dos docentes, infraestrutura das escolas e organização do sistema escolar.

O Programa Institucional de Bolsas de Iniciação à Docência (PIBID), foi elaborado a partir de uma ação coletiva do Ministério da Educação (MEC), Secretaria de Educação Superior (SESu), Coordenação de Aperfeiçoamento de Pessoal de Nível Superior (CAPES) e do Fundo Nacional de Desenvolvimento da Educação (FNDE), com a proposta de fomentar a formação docente nas Instituições de Ensino Superior (Obara et al., 2017).

O objetivo do PIBID em incentivar, mobilizar e fortalecer o processo formativo para a docência profissional no contexto das Instituições de Ensino Superior (IES), reafirma a relação entre a aprendizagem da docência e o preparo para a realização da pesquisa (Paniago \& Sarmento, 2017). Ainda segundo estes autores, o PIBID pode se constituir em um espaço adequado para o contato do licenciando com a investigação durante a formação, considerando que além de aproximá-lo da realidade da Educação Básica, motiva-o para o futuro exercício da docência com a realização de práticas vinculadas ao ensino.

Portanto, é de fundamental importância essa preocupação que se tem quanto a área da botânica, destacando que as metodologias utilizadas apresentadas nos trabalhos possuem um valor significativo para o processo de aprendizagem dos alunos e, para tanto, deve haver um processo de planejamento, escrita e reflexão acerca dos conhecimentos relacionados às metodologias para tornar o ensino eficaz e proveitoso (Dutra \& Costa Güllich, 2016).

Diante do exposto, este trabalho teve por objetivo apresentar uma metodologia de ensino na área de botânica, a partir de uma prática realizada por discentes do PIBID da Universidade Federal do Piauí - CSHNB, bem como trazer reflexões acerca dos conhecimentos relacionados às metodologias dessa área.

\section{Metodologia}

O Estudo possui caráter qualitativo, o qual aborda um estudo de caso. Segundo Ludke e André (2013) o estudo de caso é um tipo de pesquisa que envolve a interpretação do fenômeno no contexto de modo a retratar a realidade; utiliza diversas fontes de informação, as quais procuram representar pontos de vista distintos presentes numa situação social.

A aula prática foi realizada em uma turma do $2^{\circ}$ ano do Ensino Médio do Centro Estadual de Tempo Integral (CETI) Mário Martins, localizado na Cidade de Picos-PI, contemplado com o programa PIBID, no primeiro semestre de 2018. A aula foi dividida em duas etapas: preparação da aula e aplicação da aula. 
Na primeira etapa, todos os integrantes do PIBID/UFPI-CSHNB, área de Biologia (discentes, docente supervisora e o coordenador de área), que atuavam no CETI Mário Martins, realizaram uma reunião no campus Senador Helvídeo Nunes de Barros da Universidade Federal do Piauí, localizado em Picos-PI, para o planejamento das atividades a serem desenvolvidas. Baseado no conteúdo "Diversidade de Plantas", que já havia sido ministrado na escola, a equipe decidiu realizar uma aula prática. Assim foi elaborado um roteiro de execução da atividade e, posteriormente, a aquisição do material utilizado. A atividade fazia parte de um dos eixos de atuação do PIBID, sendo esse o do ensino prático pedagógico.

Levando em consideração o objetivo do PIBID e o da aula prática: aproximar o conteúdo estudado da realidade dos alunos, os materiais botânicos foram coletados em ambientes próximos a escola. Foram coletados um espécime de Briófita, um de Pteridófita e estruturas de sete espécies de Angiosperma (três monocotiledôneas e quatro eudicotiledôneas). A identificação das espécies foi realizada através de manuais de identificação.

Na segunda etapa, aplicação da aula, primeiramente foi organizada a sala, onde as plantas foram distribuídas em cima das mesas que também continham perguntas sobre cada exemplar. Em seguida, a turma foi dividida em pequenos grupos e esses percorreram todas as mesas contendo as amostras vegetais. Foram entregues uma folha de papel A4 em branco para que cada grupo escrevesse as respostas. Após a finalização de todos os grupos, os discentes integrantes do PIBID realizaram uma discussão com a turma abordando as perguntas e suas respectivas respostas corretas para fixar melhor o conteúdo.

Para a elaboração do artigo os acadêmicos integrantes do PIBID anotaram em uma ficha as percepções provenientes da comunicação verbal e não verbal dos alunos e de seu envolvimento na aula, tais como comportamentos, questionamentos, expressões corporais e comentários.

\section{Resultados e Discussão}

\section{Coleta do material botânico}

As plantas foram coletadas em três ambientes: Briófitas e Pteridófitas nas margens do Rio Guaribas (Figura 1) e as Angiospermas em um terreno baldio e no pátio do colégio. Essa estratégia de coleta de material para realização da aula prática vai de encontro com as recomendações de Sobral et al. (2018), os quais apontam que pequenos experimentos com uso de materiais fáceis de serem levados para própria sala de aula e usados corretamente, relacionando-os ao conteúdo programático de cada modalidade de ensino, poderão contribuir na melhoria da ação docente.

Os ambientes familiares aos alunos foram de suma importância para aproximar o conteúdo da realidade dos alunos. Pois segundo Ursi et al. (2018), às estratégias didáticas utilizadas pelos professores, em muitos casos, aborda-se o ensino de Botânica de forma descontextualizada, sendo esse provavelmente um dos fatores que causam maior desinteresse e dificuldade de aprendizagem por parte dos estudantes. 
Research, Society and Development, v. 10, n. 6, e30010615825, 2021

(CC BY 4.0) | ISSN 2525-3409 | DOI: http://dx.doi.org/10.33448/rsd-v10i6.15825

Figura 1. (A) Fissidens sp. - Musgos - Briófitas e (B) Selaginella sp. - Pteridófita, coletadas nas margens do rio Guaribas no município de São Luís do Piauí-PI.
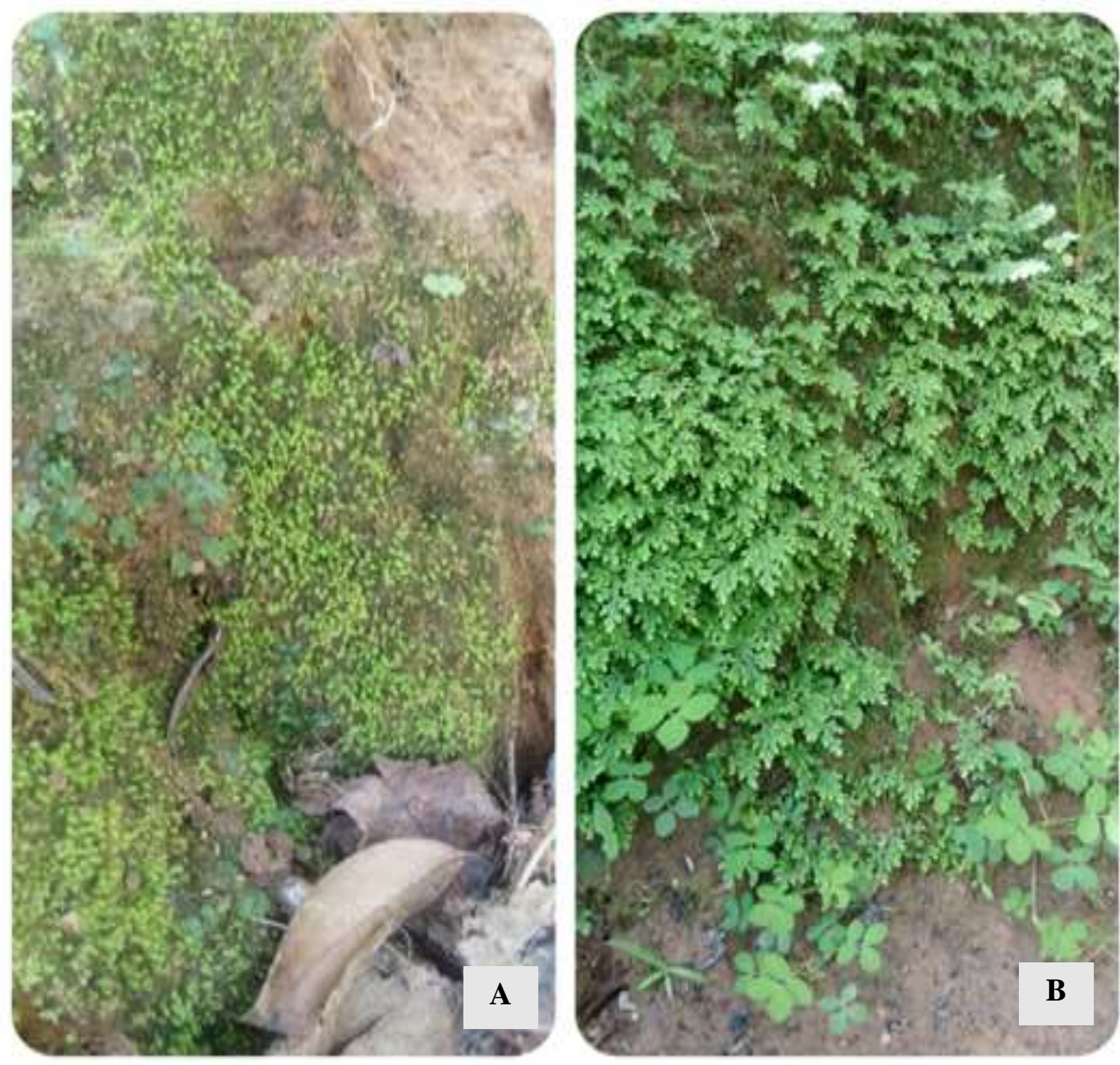

Fonte: Autores (2018).

Para atingir o objetivo da aula prática foram coletados exemplares de cada grupo de plantas: Briófitas (Figura 2 B), Pteridófitas (Figura 2 A) e Angiospermas (Figura 2 C-I). Não foi possível obter um exemplar de Gimnospermas devido à dificuldade de encontrá-lo na região semiárida piauiense. Para classificar as Angiospermas em Monocotiledôneas e Eudicotiledôneas, foram coletadas estruturas de sete espécies de plantas (Figura $2 \mathrm{C}-\mathrm{I}$ ). 
Figura 2. (A) Selaginella sp. - Pteridófita. (B) Fissidens sp. - Musgos - Briófitas. (C) Flor de Hibiscus sp. - Eudicotiledônia Angiosperma. (D) Raiz de Bidens Pilosa - Eudicotiledônia - Angiosperma. (E) Raiz de Paspalum sp. - Monocotiledônia Angiosperma. (F) Semente de Zea mays (Milho) - Monocotiledônia - Angiosperma. (G) Semente de Phaseolus vulgaris (Feijão) - Eudicotiledônia - Angiosperma. (H) Folha de Anacardium occidentale L. (Cajú) - Eudicotiledônia - Angiosperma. (I) Folha de Cymbopogon citratus (Capim-santo) - Monocotiledônia - Angiosperma.
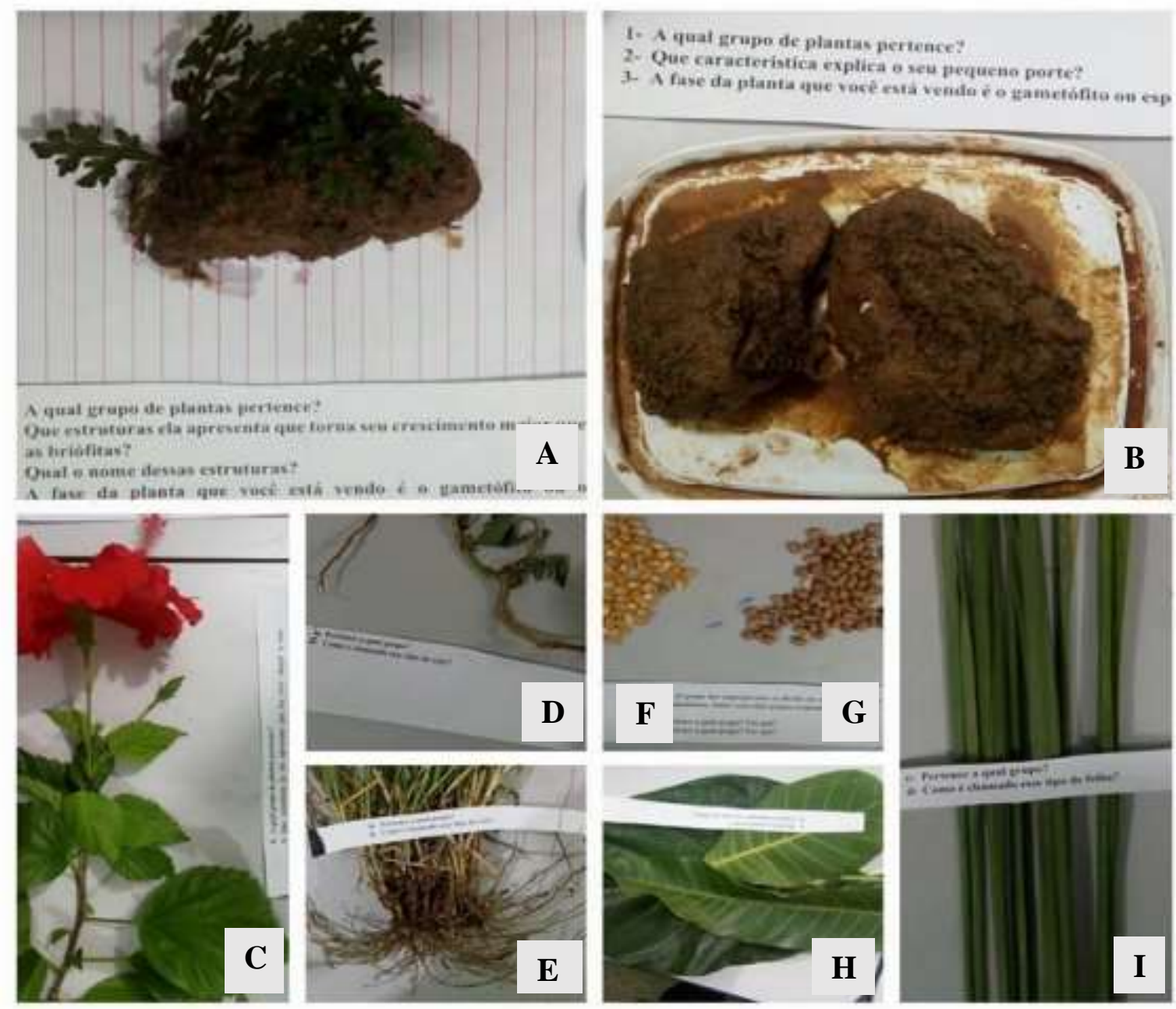

Fonte: Autores (2018).

Segundo Rebouças et al. (2020) apenas as aulas teóricas tradicionais não são capazes de aproximar os alunos e o conteúdo, principalmente os conceitos de botânica que são baseados em uma terminologia complexa e de difícil transposição para o cotidiano dos estudantes.

Silva et al. (2019), apontou que aulas com ferramentas didáticas diferenciadas funcionam como um importante recurso para despertar o interesse dos alunos para o ensino de botânica, os quais utilizaram construção de exsicatas como metodologia de ensino, demonstrando que a união do ensino teórico e prático, possibilitou o desenvolvimento de aulas mais dinâmicas, atrativas e colaborativas que aproximaram o aluno à temática em estudo.

A despeito da relevância da utilização de práticas de ensino dentro da atuação docente, o trabalho realizado por Paula; et al. (2020), aponta que são poucos os estudos que apresentam de forma sistemática que a falta de motivação dos alunos é consequência de um ensino maçante e essencialmente expositivo e, portanto, não pode ser afirmado que por esta razão o processo de ensino e aprendizagem ainda é vagaroso, tendo em vista que nem todos os professores utilizam práticas de ensino 
durante suas aulas; no entanto, não é viável afirmar que a falta de motivação dos próprios professores é o motivo de inexistência de experimentações.

\section{Dinâmica da turma}

$\mathrm{Na}$ sala de aula, as plantas juntamente com algumas perguntas sobre elas foram organizadas sobre as mesas (Figura 3). Segundo Silva e Nascimento Souza (2019), os professores possuem muitas dificuldades a serem enfrentadas no que se refere a estrutura da escola, porém esse obstáculo pode ser superado, visto que, para se realizar uma aula prática não necessita de grandes materiais e/ou de estruturas bem equipadas, podendo serem realizadas em um simples ambiente verde e até mesmo dentro da própria sala de aula

A turma foi dividida em pequenos grupos, os quais tiveram a oportunidade de responder as perguntas através da observação dos exemplares de cada material vegetal exposto. A divisão da turma em pequenos grupos para realização da aula é uma recomendação de Andrade e Massabini (2011), pois segundo esses a qualidade de uma aula com atividades práticas fica comprometida quando aplicadas há muitos alunos, pois são atividades que exigem mais atenção dos docentes, seja para orientar os alunos quanto aos conhecimentos científicos que se quer trabalhar, seja para organizar e verificar o andamento da aula, de modo a evitar situações de riscos aos alunos ou não favorecedoras da aprendizagem.

Figura 3. (A) Organização da sala para a aula prática. (B) Alunos participando da aula. (C) Monitor anotando as percepções dos alunos.
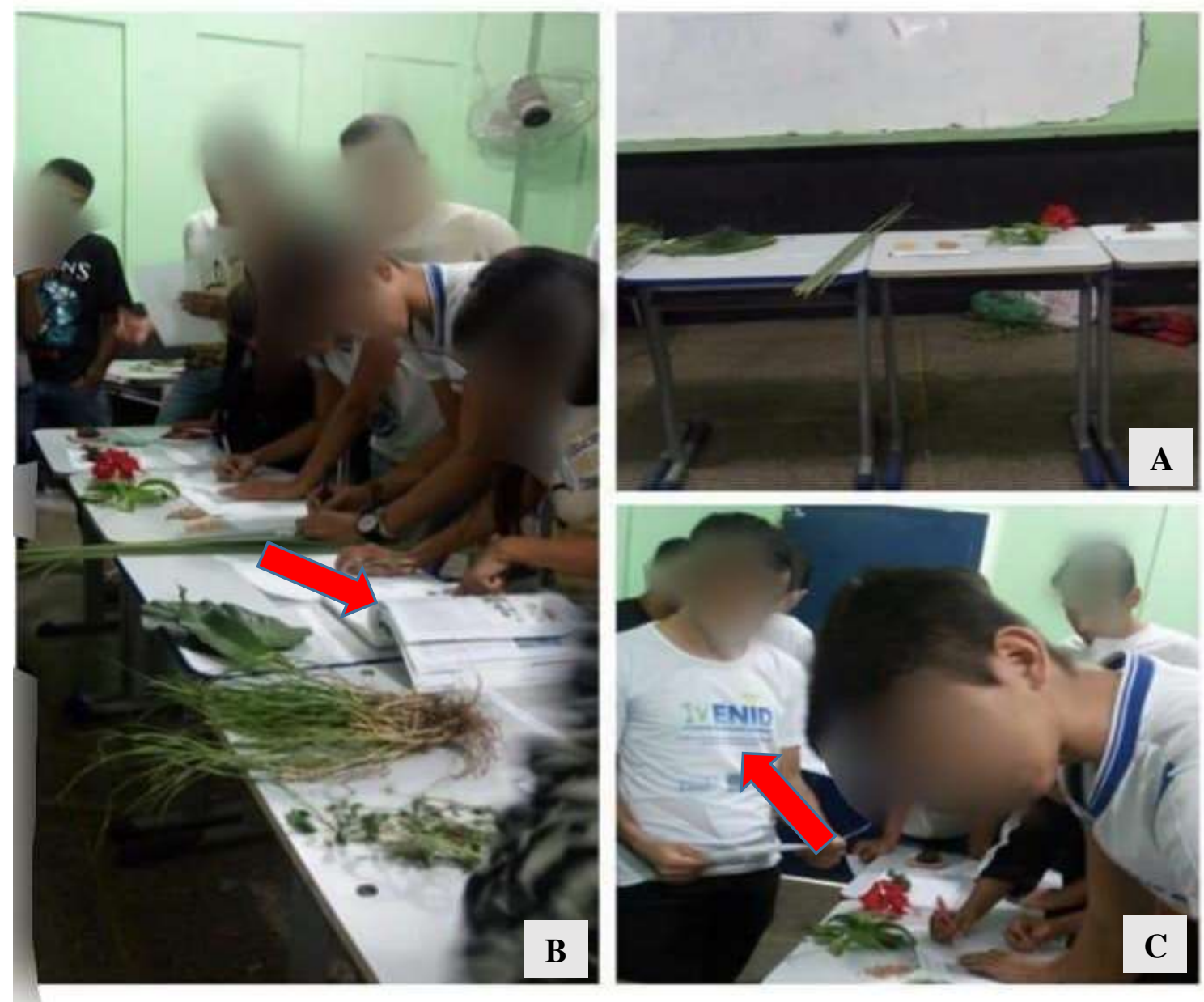

Fonte: Autores (2018). 
Na primeira mesa foram expostos os exemplares de briófitas, Fissidens sp. - Musgos, com as seguintes perguntas ao seu lado: 1) A qual grupo de plantas pertence? 2) Que característica explica o seu pequeno porte? 3) A fase da planta que você está vendo é o gametófito ou o esporófito? E de pteridófita, Selaginella sp., com suas respectivas perguntas: 1) A qual grupo de plantas pertence? 2) Que estruturas ela apresenta que torna seu tamanho maior que as briófitas? 3) Qual o nome dessas estruturas? 4) A fase da planta que você está vendo é o gametófito ou o esporófito? Na segunda mesa foram expostos o exemplar de angiospermas, Hibiscus sp., com as seguintes perguntas? 1) A qual grupo de plantas pertence? 2) Que estrutura você consegue visualizar que só pertence a esse grupo de plantas? Também foram expostas outras estruturas de plantas das angiospermas para os alunos classificarem em monocotiledôneas e eudicotiledôneas. Ainda na segunda mesa foram colocadas as sementes de Zea mays (Milho) e Phaseolus vulgaris (Feijão) para os alunos classificar em monocotiledôneas e eudicotiledôneas com as perguntas. 1) O grupo das angiospermas é dividido em dois grupos distintos: o grupo das monocotiledôneas e o grupo das eudicotiledôneas. Observe as estruturas expostas de Zea mays (Milho) e Phaseolus vulgaris (Feijão) e responda, respectivamente: a) Pertence a qual grupo? Por quê? b) Pertence a qual grupo? Por quê?

$\mathrm{Na}$ terceira mesa, dando continuidade com a classificação em monocotiledôneas e eudicotiledôneas, foram colocadas as folhas de Cymbopogon citratus (Capim-santo) e Anacardium occidentale L. (Cajú) e também suas respectivas perguntas: c) Pertence a qual grupo? d) Como é chamado este tipo de folha? d) Pertence a qual grupo? e) Como é chamado este tipo de folha?

Na quarta mesa, seguindo com a classificação em monocotiledôneas e eudicotiledôneas, foram expostas as raízes de Paspalum sp. (capim) e Bidens Pilosa (Picão) com suas respectivas perguntas: c) Pertence a qual grupo? d) Como é chamado este tipo de raiz? d) Pertence a qual grupo? e) Como é chamado este tipo de raiz?

No que se refere à dinâmica da turma e ao envolvimento dos alunos, a aula prática foi realizada com êxito, a qual contou com a participação de todos os alunos. A quantidade de acertos e erros das respostas não foi usado como critério avaliativo, pois não se adequava ao objetivo do PIBID, nem o da aula prática, os quais se referem a levar novas metodologias para sala de aula que chamem a atenção e o interesse dos alunos para o conteúdo exposto.

Segundo Rebouças et al. (2020) metodologias que aproximam os alunos das plantas vivas e suas partes facilita a compreensão dos termos, permite ressignificá-los e oportuniza o aprendizado mais significativo, além de diminuir a ocorrência do fenômeno da "Cegueira botânica".

Para a realização da aula, foi solicitado que os alunos respondessem as questões sem o uso do livro didático. No entanto, uma aluna pediu para utilizar o livro para responder as perguntas, pois não havia assistido a aula teórica com a professora titular da turma (Figura 3-B, seta vermelha) o qual foi permitido pelo monitor (discente membro do PIBID), pois seria contra o objetivo da aula e do PIBID excluir uma aluna da atividade. Essa atitude vem de encontro com o argumento apresentado por Paula et al. (2019), que apontam que é de suma importância refletir de que maneira o processo de ensino e aprendizagem ocorre, e não somente como o professor imagina que ele deva acontecer; ademais, o aluno deve sempre ter motivação para aprender e isso só será possível mediante aulas práticas e até mesmo a saída da rotina que a sala de aula faz com que o professor tenha (Paula, et al., 2020). Além disso, segundo Bortoluzzi e Coutinho (2018), o professor de Biologia deve estar atento às peculiaridades de cada aluno, para que no decorrer de uma atividade prática, as peculiaridades de cada aluno sejam levadas em consideração, aumentando assim o rendimento das atividades experimentais com seus alunos

O PIBID funciona em três eixos: 1) Eixo da monitoria; 2) Eixo das atividades complementares, 3) Eixo do ensino prático pedagógico. Assim, o planejamento das atividades deve envolver diversos recursos didáticos associados a fundamentos teóricos que visam propor um ensino de Biologia que contribua para a formação de sujeitos ativos, ou seja, que participem diretamente do processo de ensino-aprendizagem. 
O PIBID proporciona aos envolvidos - discentes, professores supervisores e coordenadores - pensar sobre a práxis docente, além de oportunizar o contato direto com a escola, com a sala de aula e vivenciar os sucessos e insucessos que envolvem o processo educativo. Para Noronha et al. (2020), as experiências agregadas durante o período de participação no PIBID promovem o sentimento de preparo mínimo para o exercício da docência para a conclusão da graduação e na inserção no mercado de trabalho.

Segundo Drumond (2020), o contato direto dos acadêmicos do PIBID com o cotidiano da escola e com a prática de professores (a) da educação básica favoreceu a construção de saberes e conhecimentos que geralmente não são adquiridos no espaço da universidade. São saberes que vêm da prática, construídos na relação com os(as) professores(as) e as alunos nas escolas.

\section{Considerações Finais}

A aula prática apresentada nesta pesquisa se mostrou bastante eficaz para a compreensão dos conceitos de Botânica relacionados ao conteúdo "diversidade de planta", bem como superar obstáculos de estrutura do sistema educacional. As plantas coletadas em ambientes próximos a escola proporcionaram aos alunos relacionar o conteúdo com o ambiente em que vivem, superando a dificuldade de realizar atividade de campo. Por ser uma atividade simples e de baixo custo é de fácil reprodução por outros docentes.

Os acadêmicos da Universidade Federal do Piauí, monitores do PIBID, encontraram grande satisfação na realização da atividade junto aos alunos da escola, pois foi uma experiência importante para sua formação profissional como Licenciandos em Ciências Biológicas, demonstrando a importância do PIBID para a formação dos professores da educação básica.

Portanto, é de fundamental importância que trabalhos realizados pelos Pibidianos gerem novos estudos para a ampliação do conhecimento relacionados com temáticas de metodologias ativas no ensino de botânica e demais áreas da biologia, bem como de outros campos de conhecimento.

\section{Agradecimentos}

Agradecemos a Coordenação de Aperfeiçoamento de Pessoal de Nível Superior, CAPES, Brasil, pela concessão de bolsas de Iniciação à Docência concedidas a autores da pesquisa.

\section{Referências}

Andrade, M. L. F., \& Massabni, V. G. (2011). O desenvolvimento de atividades práticas na escola: um desafio para os professores de ciências. Ciência \& Educação (Bauru), 17(4), 835-854. https://doi.org/10.1590/S1516-73132011000400005.

Borges, B. T., Vargas, J. D., Oliveira, P. J. B., \& Vestena, S. (2019). Aulas práticas como estratégia para o ensino de botânica no ensino fundamental. ForScience, 7(2), 2019.

Bortoluzzi, L. Z., \& Coutinho, R. X. (2018). Atividades práticas no ensino de biologia para o PROEJA. EJA em Debate, 7(11).

Burggrever, T., Mormul, N. M. (2017). A importância do PIBID na formação inicial de professores: um olhar a partir do subprojeto de Geografia da UnioesteFrancisco Beltrão. Revista de Ensino de Geografia, Uberlândia-MG, 8(15), 98-122.

Drumond, V. (2020). Aprendizagem da docência: contribuições do PIBID na formação de professores (as). Diversitas Journal, 5(4), $3272-3292$.

Dutra, A. P., \& Costa Güllich, R. I. (2016). Ensino de botânica: metodologias, concepções de ensino e currículo. Revista ENCITEC, 6(2), 39-53.

Fischer, C. H., Stumpf, E. R. T., \& Mariot, M. P. (2019). A construção de uma prática pedagógica a partir do conhecimento familiar sobre plantas medicinais. Revista Educar Mais, 3(1), 56-68.

Interaminense, B. K. S. (2019). A Importância das aulas práticas no ensino da Biologia: Uma Metodologia Interativa/The Importance of practical lessons in the teaching of Biology: An Interactive Methodology. ID on line Revista De Psicologia, 13(45), 342-354. 
Research, Society and Development, v. 10, n. 6, e30010615825, 2021

(CC BY 4.0) | ISSN 2525-3409 | DOI: http://dx.doi.org/10.33448/rsd-v10i6.15825

Lima, J. H. G., Siqueira, A. P. P., \& Costa, S. (2013). A utilização de aulas práticas no ensino de ciências: um desafio para os professores. Revista Técnico Científica do IFSC, 1(5), 486.

Ludke, M., \& Andre, M. E. D. A. (2013). Pesquisas em educação: uma abordagem qualitativa: E.P.U.

Noronha, G. N., Noronha, A. A., \& Abreu, M. C. A. (2020) Relato de vivências no Pibid: aproximações com a construção docente. Práticas Educativas, Memórias e Oralidades-Rev. Pemo, 2(3), e233748-e233748.

Obara, C. E., Broietti, F. C. D., \& Passos, M. M. (2017). Contribuições do PIBID para a construção da identidade docente do professor de Química. Ciência \& Educação (Bauru), 23(4), 979-994.

Paniago, R. N., \& Sarmento, T. (2017). A Formação na e para a Pesquisa no PIBID: possibilidades e fragilidades. Educação \& Realidade, 42(2), 771-792.

Paula, V. M., Monteiro, M. L., \& Rodrigues, T. R. (2020) Experiência de uma abordagem prática no ensino de Botânica. Revista Sítio Novo, 4(3), $204-213$.

Rebouças, N. C., Ribeiro, R. T. M., \& Loiola, M. I. B. (2020). Avaliação da aprendizagem sobre conceitos de morfologia vegetal em uma escola de ensino médio. Revista Cocar, 14(30).

Santana, S. L. C. (2011). Utilização e Gestão de Laboratórios Escolares. 194 p. Dissertação de Mestrado, 196 p. UFSM. Rio Grande do Sul. PPG QVS. Santa Maria.

Silva, F. H. M., \& Nascimento Souza, D. N. (2019). Aulas práticas de biologia no ensino médio: importância e desafios. Iv Encontro Internacional De Jovens Investigadores.

Silva, J. J. L., Cavalcante, F. L. P., Xavier, V. F., \& Gouveia, L. D. F. P. (2019). Produção de exsicatas como auxílio para o ensino de botânica na escola. Conexões-Ciência e Tecnologia, 13(1), 30-37.

Sobral, M. D. S. C., de Moura, K. M., Rocha, H. G., \& Freitas, L. R. (2018). Aulas Práticas no Ensino de Ciências: Análise da Participação do Estagiário. ID on line Revista De Psicologia, 12(39), 757-771.

Ursi, S., Barbosa, P. P., Sano, P. T., \& Berchez, F. A. D. S. (2018). Ensino de Botânica: conhecimento e encantamento na educação científica. Estudos Avançados, 32(94), 7-24. 